\title{
The Role of Science Teachers in Developing the 21st Century Skills for the Elementary School Students
}

\author{
Marwan Mohammad Abualrob ${ }^{1 *}$
}

\begin{abstract}
${ }^{1}$ Arab American University, PALESTINE
*Corresponding Author: marwan.abualrob@aaup.edu
\end{abstract}

Citation: Abualrob, M. M. (2019). The Role of Science Teachers in Developing the 21st Century Skills for the Elementary School Students. Interdisciplinary Journal of Environmental and Science Education, 15(1), e02206. https://doi.org/10.29333/ijese/6368

\begin{tabular}{ll}
\hline ARTICLE INFO & \begin{tabular}{l} 
ABSTRACT \\
\cline { 3 - 3 } Received: 15 Jan. 2019
\end{tabular}$\quad \begin{array}{l}\text { The paper measures the actual role of science teachers in developing the 21st century skills for the elementary } \\
\text { stage students in Palestine. The population consisted of all West Bank and Gaza's science 3-9 grade teachers. The } \\
\text { Revised: 14 Dec. } 2019\end{array}$ \\
Accepted: 14 Dec. 2019 & $\begin{array}{l}\text { sample comprised 560 male and female teachers who were chosen randomly. A scale was used to test 48 practices } \\
\text { across 8 major categories: Critical Thinking Skills, Collaboration Skills, Communication Skills, Innovation Skills, } \\
\text { Self -Direction Skills, Global Connections Skills, Local Connections Skills and Using Technology as a Tool for } \\
\text { Learning. Surveyed teachers reported that they advance toward these categories with a frequency of 1-3 times a } \\
\text { month, which is not quite Adequate. The findings should be sequential for educators, education planners and } \\
\text { stakeholders focused on professional development and teacher training. }\end{array}$
\end{tabular}

Keywords: 21st century skills, educational transformation, performance-based education

\section{INTRODUCTION}

Since the turn of the century, there has been profound transformations that have touched all aspects of life. Today, developments and changes in social, technological and economic areas need robust educational systems that can tap all the resources available. Failing to do so would render such systems irrelevant. As a response, today's educational systems prioritize practices that link school curriculum to the market needs as well as the future professional career. Windschitl (2009) observes that the 21st century skills help build competencies across the board, including critical thinking, thus preparing workforce for a new economy. In the age of knowledge-based economy, all individuals within a community are expected to possess the means that ensure them decent life. Thus, equipping students with the skills that enable them to survive the modern day requires teachers to be aware of the market needs, and thus incorporating within their teaching strategies modules, sometimes extracurricular, that nurture and develop such skills. One remarkable initiative toward this goal was launched in 2002 in the United States. The Partnership for 21st Century Skills Organization urges schools to integrate technology into education and make sure all resources are available to streamline education. In general, the 21 st century skills provide a structured framework that ensures students engage in the learning process and helps them build confidence, innovation and leadership. They also provide a framework for professional teacher development (Kay, 2010), which helps in reaching the best possible solutions (Beers, 2006).

Today, the pace at which these changes are taking placenot the least globalization, technological breakthroughs, scientific innovation, different requirements for labor, and stiffening competitiveness - is re-delineating the range of skills that prepare students for effective contribution to today's society (Levy \& Murnane, 2005; Stewart, 2010). One way of keeping pace with transformations over time is to consider building educational systems that are focused on honing students' skills and developing their learning to be able to meet the ongoing challenges, all for professional and personal success. At the core of that lies the conviction that dealing with such transformations requires the possession of a range of skills and competencies necessary for individuals to be able to engage in effective society-building activities.

However, many teachers still focus on back-to-basics traditional education methods. Few of them deliver education in a way that encourages critical thinking, effective communication, cooperation, negotiation and problemsolution skills. Usually, the lack of these skills is associated with poor education that has failed to cope with the rapid technological advancement.

\section{Rationale}

The Palestinian schools in the West Bank and Gaza are lagging behind in terms of technology utilization and 
innovative teaching/learning skills. Many teachers still deliver education in conventional methods that depend on memorization (Ministry of Education and Higher Education, 2017). This gap perhaps requires a comprehensive reform in the system. In the IEA's Trends in International Mathematics and Science Study (TIMSS) series of international assessments, Palestinian students tend to perform poorly in mathematics and science, even in comparison with other comparable neighboring countries in the Middle East and North Africa. It is the case that making students memorize too much is a problem in many schools in the West Bank and Gaza, and perhaps students underperform because they are stressed out by too much back-to-basics content. This is not the case of TIMSS, which focuses on analyzing, synthesizing and criticalthinking skills.

CARE International's "Skills gaps and development in the Occupied Palestinian Territory" report (2015) examined barriers to participation in the economy by young Palestinians, focusing on the skills development necessary for more inclusive, sustainable, and equitable employment and entrepreneurship. The report findings suggest the existence of a fundamental skills gap- a dissociation between employers' views of graduates' skills and the belief among educational institutions that graduates have the necessary skills to enter the workforce. The findings have also been reiterated by the Palestinian Ministry of Education's Monitoring and Evaluating Report (2017), as well as with the report by the Ministry of Planning and Administrative Development (2018). Both reports reached the conclusion that the current state of education does not help much in developing life skills.

This research measures the extent to which Palestinian science teachers at elementary schools build in their pupils the 21 st century skills. The results of the research are expected to contribute to the efforts intended to informpolicymakers at the Palestinian Ministry of Education of how schools deliver education, so that the Ministry would be able to infuse such skills within teacher and student training programs. This is a cooperative effort where higher education institutions are also expected to contribute through programs designed to produce science teachers who possess such skills and are able to deliver them to their students.

\section{LITERATURE REVIEW}

There is no one comprehensive classification of the set of 21st century skills. The skills and competencies are varied, depending on the area, culture and priorities:

1. In North America, they comprise critical thinking skills, effective communication, high productivity and digital capabilities.

2. The Partnership for 21st Century Skills Organization named 6 major competences: core subjects, 21st century content, learning and thinking skills, information and communication technologies (ICT) literacy, life skills, and 21st century assessments (Trilling \& Fadel, 2009).

3. Ravitz, Hixson, English and Mergendoller's definition (2012, p. 2): “Collaboration Skills, Critical Thinking Skills, Creativity and Innovation Skills, Communication Skills, Using
Technology as a Tool for Learning, Self-direction Skills, Local Connections, Global Connections."

These definitions, however varied, share some common themes. All are based on the premise that effective learning produces a set of preferable outcomes, the most important of which is enabling learners to acquire knowledge together with critical thinking skills (Voogt \& Roblin, 2012).

Thousands of studies on the topic from around the world do exist. Below, we narrow down our review to few studies that best serve our analysis. Gut (2011) focused on the need for integrating the 21st century skills within educational content in the schools of the United States. The author presented us with real-life models where the 21st century skills are effectively and successfully infused into the system. The content focused on themes as diverse as global awareness, financial, economic, business, entrepreneurial, and civic literacy, and health and wellness; as well as skills such as critical-thinking and problem-solving, communication and collaboration, and creativity and innovation. The author presented a set of recommendations for teachers, particularly focusing on life (soft) and career (hard) skills, namely flexibility, adaptability, self-direction, social and crosscultural interaction, productivity, accountability, and leadership.

Online resources are now being used to instill and hone 21st century skills. Miller (2009) studies the development of communication, collaboration, and digital literacy skills of students at American high schools using social network tools. The author's starting point was a premise that high school and universities do not equip graduates with such skills and that employers always complain that their employees lack the practical skills that adequately prepare them for the job. Miller offers a model through which high schools can incorporate social network tools (Facebook, Diigo, Google Sites, Google Docs, and Twitter) into traditional learning environments to build the 21st century skills. Miller found that the target students were able to develop collaborative learning, research skills, and effective public communication skills.

Locally, a study by Naqa (2011) measured infusion of critical thinking skills at high schools in Khan Younis, Gaza. The findings suggest poor critical thinking content. Naqa reasons that a host of factors might be invoked:"large number of students in classrooms, many units within textbooks, no critical thinking integration in lower stages (elementary schools), teachers' indifference toward nurturing such skills, students' focus on grades rather than on skills, and absence of skill-based assessment methods" (Abualrob, 2019, p. 109).

However, two studies came with starkly contrast findings. The first was by Zidan and Odeh (2007). The authors measured the science teachers' integration of critical thinking skills at elementary schools in Hebron, West Bank. They found that creative content is particularly significant and that students, as a result, have high critical thinking skills. A more recent study by Abualrob (2019) explored the factors influencing the development of 21 st century skills in the elementary stage science students in Palestine. The author concluded that the efforts toward fostering the $21^{\text {st }}$ century skills in Palestine have of late seen improvement, which, however, remains slow and unlikely to indicate a breakthrough in the offing. 


\section{Study Question}

The study is designed to answer the following question: To what degree, if any, do Palestinian science teachers at elementary schools foster in their pupils the key 21st century skills of technology utilization, communication, innovation, self-direction, collaboration, local and global connectiveness, and critical thinking?

\section{Methodology}

This paper is part of a broader effort meant to measure the extent to which the 21 s century skills are being incorporated into teaching elementary school students in Palestine. The series of studies, with the present research being the second, used a questionnaire to collect data about the target population.

\section{Statistical Testing}

As part of the extended study that we started earlier- with the present study being the second of the series, we measure the role of science teachers in developing the 21st century skills- for the elementary school students using one sample $t$ test to determine whether the sample has been generated by a process with a specific mean.

\section{Population and Sample}

The study population comprised all science teachers in Palestine's elementary schools (3-9 grades), while the study subjects consisted of 560 male and female West Bank's teachers who were chosen based on stratified sampling for the purposes of the study (Abualrob, 2019).

\section{Study Tools}

The present study used a tool first designed by the International Innovative Teaching and Learning Study (Shear, Novais, Means, Gallagher, \& Langworthy, 2010) and later modified by Ravitz et al. (2012) to test the feasibility of " 48 practices across 8 major categories: Critical Thinking Skills, Collaboration Skills, Communication Skills, Innovation Skills, Self-Direction Skills, Global Connections, Local Connections and Using Technology as a Tool for Learning” (Abualrob, 2019, p. 110). This same tool was used later by many researchers (e.g. Tindowe et al., 2017). The scale involves five codes as to the frequency of incorporating 21 st century skills (almost daily, 13 times a week, 1-3 times a month, a few times a semester, and almost never). The sample teachers responded to each item by choosing one alternative that best describes their practice.

\section{Consistency of Tool}

Apart from the Ravitz scale- that was used for the consistency of data (with internal consistency of 0.90-0.95), the author administered a pilot survey of 30 science teachers to so that efficiency in testing and is ensured and the survey questionnaire is verified prior to executing the large-scale survey. The consistency coefficient was calculated using a Cronbach's alpha with a value of $0.81-0.85$, which is indicative for the purposes of the study (Abualrob, 2019).

\section{Validity and Reliability of the Survey}

To ensure the high quality of the survey in terms of content, relevance and proper data collection, the author gave the survey to experienced reviewers from the faculty members at Arab American University-Palestine. Based on their feedback, some items were modified in terms of word choice and phrasing.

\section{Statistical Standard}

The study used the median absolute deviation to measure statistical dispersion and the variability of the data sample to interpret the answers of respondents: (Kotrlik and Redmann, 2009):

1. Scale $1=$ Almost never, $2=$ A few times a semester, $3=$ 1-3 times per month, $4=1-3$ times per week, and $5=$ Almost daily.

2. Scale interpretation: $1-1.49=$ Almost never, $1.50-2.49$ $=\mathrm{A}$ few times a semester, $2.50-3.49=1-3$ times per month, $3.50-4.49=1-3$ times per week, and 4.50-5.00 = Almost daily.

\section{RESULTS AND DISCUSSION}

Table 1 shows that the mean of the total score of the eight categories is 3.2010. The frequency of delivering education that fosters the 21 st century skills is $1-3$ times per month. Collaboration came first at a mean of 3.4905 (1-3 times per month), slightly ahead of Critical Thinking, with a mean of 3.4833 (1-3 times per month). On the other hand, education was found lagging behind in terms of fostering Global Communication: with a mean of 2.4262 and a frequency rate of few times a semester.

Table 1. Mean, standard deviation and frequency rate of the 8 categories

\begin{tabular}{lccc}
\hline Category & Mean & $\begin{array}{c}\text { Std. } \\
\text { Deviation }\end{array}$ & Frequency rate \\
\hline Collaboration skills & 3.4905 & .71772 & $1-3$ times per month \\
\hline Critical thinking skills & 3.4833 & .73049 & $1-3$ times per month \\
\hline $\begin{array}{l}\text { Creativity and } \\
\text { innovation skills }\end{array}$ & 3.4686 & .75946 & $1-3$ times per month \\
\hline Communication skills & 3.4514 & .76764 & $1-3$ times per month \\
\hline $\begin{array}{l}\text { Using technology as a } \\
\text { tool for learning }\end{array}$ & 3.2821 & .85844 & $1-3$ times per month \\
\hline Self-direction skills & 3.1143 & .84439 & $1-3$ times per month \\
\hline Local connections & 2.8914 & .83142 & $1-3$ times per month \\
\hline Global connections & 2.4262 & .89061 & A few times a semester \\
\hline Total & 3.2010 & 0.64558 & $1-3$ times per month \\
\hline
\end{tabular}

A one sample $t$ test was administered to measure the development of the 21st century skills and test whether the mean for such skills is significantly different from 3.5, the generally accepted level for Palestinian students, with values at or above the point being statistically significant and positively indicative. As the figures in Table 2 show, the t test value $(\mathrm{t}=-10.961, \mathrm{p}$-value $=0.000$ ) was found highly significant, and well below the cutoff point (the one accepted for the purpose of this research); yet it is negatively correlated, suggesting a negative role of teachers in nurturing the 21st Century Skills for the Elementary School Students.

Table 2. Results of one sample $t$ test for the role of science teachers in developing the 21 st century skills

\begin{tabular}{lcccc}
\hline & Mean & $\begin{array}{c}\text { Std. } \\
\text { deviation }\end{array}$ & T-Value & P-Value \\
\hline $21^{\text {st }}$ Century Skills & 3.2010 & 0.64558 & -10.961 & .000 \\
\hline
\end{tabular}


Table 3. Results of one sample t test for the role of science teachers in developing collaboration

\begin{tabular}{llcccc}
\hline No. & Statement & Mean & Std. Deviation & T-Value & P-Value \\
\hline Q7 & Work in pairs or small groups to complete a task & 4.0857 & .82437 & 16.814 & .000 \\
\hline Q8 & Work with other students to set goals and create a plan for their team & 3.3857 & .94640 & -2.858 & .004 \\
\hline Q9 & Create joint products using contributions from each student & 3.3286 & 1.13139 & -3.586 & .000 \\
\hline Q10 & Present their group work to the class, teacher or others & 3.1143 & .95018 & -9.606 & .000 \\
\hline Q11 & Work as a team to incorporate feedback on group tasks or products & 3.2714 & 1.04183 & -5.192 & .000 \\
\hline Q12 & Give feedback to peers or assess other students' work & 3.7571 & .83631 & 7.276 & .000 \\
\hline \multicolumn{2}{c}{ Average } & 3.4905 & .71772 & -.314 & .754 \\
\hline
\end{tabular}

Table 4. Results of one sample t test for the role of science teachers in developing critical thinking skills

\begin{tabular}{|c|c|c|c|c|c|}
\hline No. & Statement & Mean & Std. Deviation & T-Value & P-Value \\
\hline Q1 & Compare information from different sources before completing a task or assignment. & 3.2000 & .95104 & -7.465 & .000 \\
\hline Q2 & Draw their own conclusions based on analysis of numbers, facts, or relevant information. & 3.5286 & 1.05276 & .642 & .521 \\
\hline Q3 & Summarize or create their own interpretation of what they have read or been taught. & 3.8857 & 1.05033 & 8.690 & .000 \\
\hline Q4 & Analyze competing arguments, perspectives or solutions to a problem. & 3.4143 & .99362 & -2.041 & .042 \\
\hline Q5 & Develop a persuasive argument based on supporting evidence or reasoning. & 3.3143 & 1.09044 & -4.030 & .000 \\
\hline \multirow[t]{2}{*}{ Q6 } & $\begin{array}{l}\text { Try to solve complex problems or answer questions that have no single correct solution } \\
\text { or answer. }\end{array}$ & 3.5571 & .96650 & 1.399 & .162 \\
\hline & Average & 3.4833 & .73049 & -.540 & .589 \\
\hline
\end{tabular}

The same t test was also carried out for collaboration skills. The values were found insignificant $(\mathrm{t}=-.314$, $\mathrm{p}$-value $=.754)$. In details, four of the items were well below the cutoff point, while two had high significance, well above the cutoff point. In general, however, the figures suggest insignificant role of teachers in building the skills within this category (the average mean for all items is lower than the accepted level set for the purposes of this research). The figures for developing collaboration skills (mean $=3.4905$, standard deviation $=.71772$, frequency rate $=1-3$ times a month) are still below the cutoff point 3.5 , and thus unpromising. Of the six practices within this category, two had remarkably significant values: "Work in pairs or small groups to complete a task" (mean=4.0857), and "Give feedback to peers or assess other students' work" (mean=3.7571). Other practices had a mean range of 3.11433.3857 (see Table 3).

Although the curriculum has been built to foster collaboration (which is crucial for effective teaching/learning), collaboration has yet to be given due attention by science teachers. Reasons for this discrepancy could range from overcrowded classrooms (and thus low teacher-to-student ratio), to poor assessment system, to the heavy teaching burden.

However, the personal attitude of the teacher remains the main culprit. It seems that science teachers are not aware of the power of cooperation; hence their indifference about designing collaboration activities. After all, students need a reason to cooperate. Presenting them with a challenging activity is likely to unleash their positive attitudes toward collaboration. Unfortunately, science teachers at elementary schools in Palestine do not seem to appreciate that young students do have the ability to work cooperatively to tackle a problem or deal with a challenging activity.

In terms of the efforts toward building the critical thinking skills, the one sample t test results show that the average mean (3.4833) is a little below the accepted level, while the items average is insignificant $(\mathrm{t}=-.540$, $\mathrm{p}$-value=.589). As shown in Table 4, three of the items were significant (with negative values), while only one item exhibited strong positive significance. In general, however, the figures suggest an insignificant role of teachers in building the skills within this category (the average mean for all items is higher than the accepted level set for the purposes of this research).

Of course, critical thinking cannot be taught overnight, and children cannot be said to have the rigid reasoning of the adults. However, the practice of a successful teacher can always provide the students with the right conditions and opportunities, creating for them a motivating, enabling environment. Students, thus, cannot be fully blamed for lacking critical thinking. Developing this skill needs teachers who are familiar with successful practice, knowing exactly not only what to teach, but also how to present the material for the students. The teacher can always teach students that critical thinking can also be obtained from a range of other sourcesin addition to the teacher- including parents, classmates, experts, peers, and all people they come in contact with.

The total average for the teachers' role in developing the innovation skills was found insignificant $(t=-.980, p$-value $=.327$ ), with the mean a little lower than the accepted level of 3.5. As shown in Table 5, two of the items were negatively correlated and two were positively correlated. Developing innovation, is not much better than the first two categories, yet it is relatively promising, but with the same frequency rate (1-3 times a month). Though the 3.4686 mean is still below the target, in two of the practices ("Create a solution to a complex, open-ended question or problem", and "Generate their own ideas about how to tackle a problem or question"), teachers seem to have delivered adequate feed into these sub-skills (with 3.7429 and 3.6143, respectively).

These results suggest that students are not adequately able to come up with new and original ideas. It is not necessary that every student be innovative, but to survive in the 21 st century people need to show more creativity. The relatively low innovation figures (see Table 5) might be attributed to the educational system, with teachers adopting methods designed to nurture safe, non-challenging experiences. While it is undoubtedly not fair to exclusively blame teachers, there are many things teachers can do to nurture imagination among 
Table 5. Results of one sample $t$ test for the role of science teachers in developing innovation skills

\begin{tabular}{|c|c|c|c|c|c|}
\hline No. & Statement & Mean & Std. Deviation & T-Value & P-Value \\
\hline Q18 & Use idea creation techniques such as brainstorming or concept mapping & 3.4286 & .96554 & -1.751 & .081 \\
\hline Q19 & Generate their own ideas about how to tackle a problem or question & 3.6143 & 1.04692 & 2.583 & .010 \\
\hline Q20 & Test out different ideas and work to improve them & 3.2000 & .93587 & -7.586 & .000 \\
\hline Q21 & Create a solution to a complex, open-ended question or problem & 3.7429 & .98192 & 5.853 & .000 \\
\hline Q22 & Create an original product or performance to express their ideas & 3.3571 & .89580 & -3.774 & .000 \\
\hline & Average & 3.4686 & .75878 & -.980 & .327 \\
\hline
\end{tabular}

Table 6. Results of one sample t test for the role of science teachers in supporting the use of technology

\begin{tabular}{|c|c|c|c|c|c|}
\hline No. & Statement & Mean & Std. Deviation & T-Value & P-Value \\
\hline $\mathrm{Q} 41$ & Use technology or the internet for self-instruction & 4.1143 & .99434 & 14.619 & .000 \\
\hline $\mathrm{Q} 42$ & Select appropriate technology tools or resources for completing a task & 3.9000 & .98867 & 9.574 & .000 \\
\hline Q43 & Evaluate the credibility and relevance of online resources & 3.1714 & 1.19596 & -6.501 & .000 \\
\hline Q44 & Use technology to analyze information & 2.6286 & 1.13707 & -18.136 & .000 \\
\hline $\mathrm{Q} 45$ & Use technology to help them share information & 3.4000 & 1.06195 & -2.228 & .026 \\
\hline $\mathrm{Q} 46$ & Use technology to support team work or collaboration & 3.1000 & 1.20998 & -7.823 & .000 \\
\hline Q47 & Use technology to interact directly with experts or members of local/global communities. & 2.8286 & 1.26572 & -12.553 & .000 \\
\hline \multirow[t]{2}{*}{ Q48 } & Use technology to keep track of their work on extended tasks or assignments & 3.1143 & 1.32722 & -6.877 & .000 \\
\hline & Average & 3.2821 & .85894 & -6.002 & .000 \\
\hline
\end{tabular}

Table 7. Results of one sample t test for the role of science teachers in building Self-Direction Skills

\begin{tabular}{|c|c|c|c|c|c|}
\hline No. & Statement & Mean & Std. Deviation & T-Value & P-Value \\
\hline Q23 & Take the initiative when confronted with a difficult problem or question & 3.4857 & 1.02551 & -.330 & .742 \\
\hline Q24 & Choose their own topics of learning or questions to pursue & 3.2429 & .93335 & -6.520 & .000 \\
\hline Q25 & Plan the steps they will take to accomplish a complex task & 3.1429 & .94630 & -8.931 & .000 \\
\hline Q26 & Choose for themselves what examples to study or resources to use & 2.9286 & 1.15145 & -11.744 & .000 \\
\hline Q27 & $\begin{array}{l}\text { Monitor their own progress towards completion of a complex task and modify their work } \\
\text { accordingly }\end{array}$ & 2.9714 & 1.13455 & -11.025 & .000 \\
\hline $\mathrm{Q} 28$ & Use specific criteria to assess the quality of their work before it is completed & 2.9571 & 1.07581 & -11.941 & .000 \\
\hline Q29 & Use peer, teacher or expert feedback to revise their work & 3.0714 & 1.17605 & -8.624 & .000 \\
\hline & Average & 3.1143 & .84439 & -10.810 & .000 \\
\hline
\end{tabular}

young learners. The Palestinian students' acquisition of innovation skills in science subjects requires teachers to create strategies based on active project-based learning and inquiry.

As shown in Table 6, the $t$ test value for the use of technology $(\mathrm{t}=-6.002$, $\mathrm{p}$-value $=0.000)$ was found significant, with two items exhibiting high positive values and six showing high negative values. These figures suggest that the role of teachers in encouraging the use of technology as a tool for learning was not particularly helpful, with the mean far below the target (mean=3.2821), again with a frequency rate of $1-3$ times a month. Out of eight sub-categories, two- "Use technology or the internet for self-instruction" and "Select appropriate technology tools or resources for completing a task"- received scores higher than the cut point (4.1143 and 3.9000, respectively).

Three reasons might explain these humble figures. First, schools still depend largely on textbooks as the main source of teaching/learning. Second, the test-based assessment system seems to have restricted the use of technology. Third, although the Ministry of Education has provided teachers with training on the use of technology (Intel courses), teachers have yet to acquire adequate skills necessary for using technology in education.

Palestinian educators need to know that to produce productive graduates, classrooms should be equipped with digital learning tools, such as computers, internet access, online learning materials and LCDs. The use of technology improves student engagement and motivation and speeds up learning. Nowadays, this has been made possible through tools that connect students with teachers, who would then be able to provide students with professional content and resourcesthus allowing students to personalize learning.

The figures for developing self-direction skills are very close to those related to the use of technology. As shown in Table 7 , the $t$ test value $(t=-10.810, p$-value $=0.000)$ is significant (with the seven items within this category exhibiting significant negative values), while the mean remains below the cutoff point. A mean of 3.1143 does not reflect effective involvement with practices that foster making decisions and managing one's own learning activities. Even the most salient practice within this category ("Take the initiative when confronted with a difficult problem or question") could not stand the cut point test (only 3.4857). Giving an account of this failure shouldn't be difficult. Young learners, it appears, have got used to a conventional method whereby the teacher is the center of the process and the students are only receivers. They depend on the teacher for decision-making and managing activities within the classroom. Probably this is the reason why many students seek knowledge outside the school system, often through tutoring.

The teachers' role in nurturing local connections skills is worrying. Table 8 shows a mean of 2.8914 , well below the standard, and even the best actual practice ("Apply what they are learning to local situations, issues or problems”) could not make it to the cut point. The $\mathrm{t}$ test value $(\mathrm{t}=-17.337, \mathrm{p}$-value 
Table 8. Results of one sample t test for the role of science teachers in developing Local Connections Skills

\begin{tabular}{|c|c|c|c|c|c|}
\hline No. & Statement & Mean & Std. Deviation & T-Value & P-Value \\
\hline Q36 & Investigate topics or issues that are relevant to their family or community & 2.9429 & 1.06847 & -12.340 & .000 \\
\hline Q37 & Apply what they are learning to local situations, issues or problems & 3.5143 & 1.14424 & .295 & .768 \\
\hline Q38 & Talk to one or more members of the community about a class project or activity & 2.9000 & .98867 & -14.361 & .000 \\
\hline Q39 & Analyze how different stakeholder groups or community members view an issue & 2.4429 & 1.11757 & -22.385 & .000 \\
\hline \multirow[t]{2}{*}{ Q40 } & $\begin{array}{l}\text { Respond to a question or task in a way that weighs the concerns of different community } \\
\text { members or groups }\end{array}$ & 2.6571 & 1.08178 & -18.438 & .000 \\
\hline & Average & 2.8914 & .83067 & -17.337 & .000 \\
\hline
\end{tabular}

Table 9. Results of one sample t test for the role of science teachers in developing Global Connections Skills

\begin{tabular}{|c|c|c|c|c|c|}
\hline No. & Statement & Mean & Std. Deviation & T-Value & P-Value \\
\hline Q30 & Read about other countries or cultures & 2.1857 & 1.04692 & -29.708 & .000 \\
\hline Q31 & Use information or ideas that come from people in other countries or cultures & 2.2429 & 1.08903 & -27.317 & .000 \\
\hline Q32 & $\begin{array}{l}\text { Discuss issues related to global interdependency (for example, global environment trends, } \\
\text { global market economy) }\end{array}$ & 2.4571 & 1.11821 & -22.070 & .000 \\
\hline Q33 & Understand the life experiences of people in neighboring cultures & 2.7429 & 1.14352 & -15.669 & .000 \\
\hline Q34 & Read about the geography of distant countries & 2.2429 & .99279 & -29.965 & .000 \\
\hline Q35 & Reflect on how their own experience and local & 2.6857 & 1.00863 & -19.105 & .000 \\
\hline & Average & 2.4262 & .89061 & -28.532 & .000 \\
\hline
\end{tabular}

Table 10. Results of one sample t test for the role of science teachers in developing Communication Skills

\begin{tabular}{|c|c|c|c|c|c|}
\hline No. & Statement & Mean & Std. Deviation & T-Value & P-Value \\
\hline Q13 & $\begin{array}{l}\text { Structure data for use in written products or oral presentations (e.g., creating charts, } \\
\text { tables or graphs) }\end{array}$ & 3.4714 & 1.01116 & -.669 & .504 \\
\hline Q14 & Convey their ideas using media other than a written paper (e.g., posters, video, blogs, & 3.2857 & 1.00293 & -5.056 & .000 \\
\hline Q15 & Prepare and deliver an oral presentation to the teacher or others & 3.2429 & .94856 & -6.415 & .000 \\
\hline Q16 & Answer questions in front of an audience & 3.9143 & 1.15668 & 8.476 & .000 \\
\hline Q17 & Decide how they will present their work or demonstrate their & 3.3429 & 1.02750 & -3.619 & .000 \\
\hline & Average & 3.4514 & .76764 & -1.497 & .135 \\
\hline
\end{tabular}

$=0.000$ ) was found significant, with four of the five items showing significant negative values. If anything, there is lack of cooperation between schools and the local communities. The Palestinian society still sees schools as the only source for gaining knowledge, and people assume that the school can deliver effective education independently of other players outside the educational system. Brought up to believe that children remain dependent on others, parents don't believe that their children can manage their issues by themselves or create their own learning activities. This is a gap that needs to be addressed at the national level. Developing local connection skills in students needs authentic connections between schools and the Ministry of Education, on the one hand, and families, community groups and nongovernmental organizations, on the other.

As shown in Table 9, Nurturing global connections skills was even worse (mean=2.4262, SD.89061) across the board. Although this category shares the same frequency rate with other clusters (1-3 times a month), none of its practices has positive significant values. The result of the $t$ test $(t=-28.532$, $\mathrm{p}$-value $=0.000$ ) suggested that all the items have negative significant values.

The Palestinian society already suffers unrest and is steeped with challenges and turmoil (Israeli occupation, high unemployment rates, poverty, internal divide, non-control over own resources, etc.). Such internal problems are restricting identification with global issues. On the other hand, science teachers believe that fostering global connection skills is the job of humanities teachers. In a model of best practices, however, all teachers should embed within the activities modules that address global awareness issues. This can be done through curricular practice and extracurricular initiatives. Teachers who are keen to building global connections skills in their students would always present their students with experiences that bring them face to face with global issues, such as poverty, climate change and different lifestyles across cultures.

Finally, surveyed science teachers seem to have exerted more efforts in developing their students' communication skills, though the level is still unsatisfactory. A remarkable value can be seen for one practice ("Answer questions in front of an audience”), with a mean of 3.9143 , which is promising. However, the negative values for the rest of practices rendered the overall mean of the category substandard (albeit marginally below the cutoff point). Looking at the t test value $(t=-1.497, p$-value $=.135)$ in Table 10 , one can clearly see three out of four items exhibiting negative correlation.

Failure in fostering communication skills can result from wrong teaching practices. First, a teacher who scrimps on creating a conversation, where students are involved, is actually suppressing one of the most essential communication skills: speaking. Second, a teacher who does not present his/her students with material for discussion is unlikely to build listening skills in his/her students. Third, a teacher who does not encourage group-built activities (which allow students to work in groups, thereby minimizing pressure) cannot improve learners' oral and even written communication skills. 


\section{CONCLUSION}

The 21st century skills are being recognized increasingly worldwide. However, our findings signal a humble role of teachers in improving our young learners' 21st century skills, which are essential to effective participation in society development. Science teachers' nurture of 21 st century skills for elementary stage students in Palestine is still unsatisfactory (mean $=3.2010, \mathrm{SD}=0.64558$ ). The frequency of delivering education that fosters such competencies is 1-3 times per month, which is inadequate. With this level of teacher intervention, school students won't be adequately prepared for life challenges. If anything, science teachers at West Bank and Gaza elementary schools do not effectively foster the development of the 21 st century competencies. The results of the survey suggest that the elementary stage science teachers clearly focus on delivering general knowledge rather than building skills. It seems that science teachers emphasize memorization of isolated facts; they rely heavily on textbooks without taking into account student understanding; they allow for limited student questions or comments in classroom discourse. This results in repressing critical skills and harms the ability of students to link concepts to real life experiences (Carlsen, 1991).

However, there is still a promising potential to the results. One could imagine learners' performance if they were allowed more time to practice such skills. An overall frequency of 1-3 times a month will never be adequate to cultivate new skills. The promotion of sustainable creative skills needs more time, more feed and more dedication on the part of the teacher.

There are some unprofessional behaviors that teachers show when they carry out their teaching practices. This requires a change in the teachers' attitudes and their philosophy of teaching. The change could be possible through system reforms that take into consideration building constructive, active and student-centered learning. In the process, it is important to break with the traditional test-based system and turn to real performance-based assessment.

Palestinian science teachers, it seems, have adopted curriculum-based teaching learning/learning strategies. It is important to abandon such approaches, moving ahead to performance-based methods that allow the students to move smoothly from the simple to the complex. The biggest challenge for educators is the absence of well-defined approaches to teaching such skills. In this case, it is the role of the teacher to know how and when to infuse the 21 st century skills into the classroom practice. The starting point should be working on the part of the teachers to improving their own skills. This will have to do with extensive training which can be provided by the supervisory bodies (the Ministry of Education). Alternatively, teachers can use their own resources (for example, online resources) to build their competences, which will later be delivered to young learners. Today, with almost all Palestinian homes connected to the internet, this should be possible.

Preparing students to mastering 21st century skills requires well trained teachers who draw on advances in interdisciplinary fields. Teachers, for example, are expected to be well acquainted with ICT skills. This is, unfortunately, not the case with many science teachers in the West Bank and Gaza elementary schools; and many still use traditional methods. Where this is the case, young learners are marginalized to fact memorization. The result is that young learners can only reproduce whatever they have learned, but may be unable to develop critical thinking or innovation.

The foregoing discussion suggests that teachers are the main agents of change. If they are enthusiastic enough, then it is a matter of time before such skills are acquired by their students. However, we should not overlook the role of other players.

At the national level, the Ministry of education could carry out extensive research to identify the nature of such skills as well as the best ways to develop them. Identifying the nature of these competences should be the first step. To train students on all these competencies, the 21st century skills should be incorporated within the science core curriculum. Those who have built the Palestinian elementary school curriculum might have assumed that teachers possess the skills and training necessary to foster the development of the 21st century skills. However, when it comes to infusing new skills, there is always a gap- not the least because the curriculum itself does not include adequate material for practice, and the teachers are often left to create their own activities. It is, therefore, essential to revisit the curriculum, making sure it includes clear instructions, material and activities that deal directly with 21 st century skills.

Individual schools also have a role to play. The management should make available all the resources needed to create an environment in which students participate earnestly in the learning process. The physical environment is important. An enabling one will naturally have labs with personal computers, internet access points, LCDs, projectors, etc. Such an environment would be appealing even for the poorly-performing learners.

All these agents must cooperate to foster the development of the 21st century skills. Once all resources are available, it shouldn't be difficult to reach goals. At the critical thinking level, students need to process the generated data. Now because by nature science is based on inquiry, learners need to make reasoning and be able to make judgments about what is logical and what is not. In terms of collaboration, in order to do an activity in the right way, learners should interact effectively in such a way that allows easy flow of information. This will help them work independently of the teacher and become self-directed; and it facilitates communication and fosters innovation as well. This can always be done with the help of technology, where students have access to computerbased resources as well as online material, and even social networks. This was made easier with information building and distribution methods: a simple Microsoft Word document, a podcast, a blog, etc. Now adding some aspects from other fields of knowledge should be possible. Many of science topics can be extended toward local or global awareness. For example, linking the result of a specific activity to implications for the local or global environment can be quite easy. At this stage, the teacher might work as a facilitator, giving help to students once they ask for it. 


\section{ACKNOWLEDGEMENT}

I would like to thank Dr. Mahmoud Almanassra for Reviewing the statistics part of this paper.

\section{REFERENCES}

Abualrob, M. (2019). Determinants of Building 21st Century Skills in Palestinian Elementary Schools. Higher Education Studies, 9(2), 108-116.

Beers, S. (2006). 21st century skills preparing students for their future. Retrieved from https://cosee.umaine.edu/files/ coseeos/21st century skills.pdf

CARE International. (2015). Skills gaps and development in the Occupied Palestinian Territory. Retrieved from http://www.awrad.org/files/server/care\%20english\%20rep ort\%20\%202015.pdf

Carlsen, W. S. (1991). Effects of new biology teachers' subject matter knowledge on curricular planning. Science Education, 75(6), 631-647. https://doi.org/10.1002/sce. 3730750605

Gut, D. M. (2011): Integrating 21st Century Skills into the Curriculum. In Wan, Guofang, Gut, Dianne M. (Eds.), Bringing Schools into the 21st Century, 137-157. https://doi.org/10.1007/978-94-007-0268-4_7

Kay, K. (2010). 21st century skills: Why they matter, what they are, and How we get there? Retrieved from http://learning thenow.com/blog/wp-content/uploads/2010/10/Ken-Kay21st-Century-Skills-Why-They-Matter-What-They-Areand-How-We-Get-There-pdf1.pdf

Kotrlik, J., \& Redmann, D. (2009). A trend study: Technology adoption in the teaching-learning process by secondary Agri science teachers. Journal of Agricultural Education, 50(2), 62-74. https://doi.org/10.5032/jae.2009.02062

Levy, F., \& Murnane, R. (2005). The new division of labor: How computers are creating the next job market. Princeton, NJ: Princeton University Press. https://doi.org/10.1515/ 9781400845927

Metiri Group \& NCRET. (2003). EnGauge 21st century skills: Literacy in the digital age. Chicago, IL: NCREL. Retrieved from http://pict.sdsu.edu/engauge21st.pdf

Miller, R. (2009). Developing 21st Century Skills Through the Use of Student Personal Learning Networks. Arizona: Northcentral University. Retrieved from http://search. proquest.com/docview/305177755 ?accountid=37552

Ministry of Education and Higher Education. (2017). Monitoring and Evaluating Report. Ramallah, Palestine.
Ministry of Planning and Administrative Development. (2018). Report on the Millennium Development Goals. Ramallah, Palestine.

Naqa, S. (2011). The level of creative thinking among students in high school in the scientific culture and the degree of encouraging science teachers to them from their point of view. IUG Journal of Humanities Research, 19(1), 167-207. Retrieved from http://www.iugaza.edu.ps/ar/periodical/

Partnership for 21st century skills- P21 (2009). Framework for 21st century learning. Retrieved from http://www.p21.org/ storage/documents/1._p21_framework_2-pager.pdf

Ravitz, J., Hixson, N., English, M., \& Mergendoller, J. (2012, April). Using project based learning to teach 21st century skills: Findings from a statewide initiative Paper presented at Annual Meetings of the American Educational Research Association, Vancouver, BC. Retrieved from https://www.researchgate.net/publication/258188193_Usi ng_project_based_learning_to_teach_21_st_century_skills Findings_from_a_statewide_initiative_Jason_Ravitz_Buck_I nstitute_for_Education

Shear, L., Novais, G., Means, B., Gallagher, L., \& Langworthy, M. (2010). ITL research design. Menlo Park, CA: SRI International.

Stewart, V. (2010). A classroom as wide as the world. In Curriculum 21: Essential Education for a Changing World, Hayes Jacobs (ed.), 97-114. Alexandria, VA: Association for Supervision and Curriculum Development.

Tindowen, D., Bassig, J., \& Cagurangan, J. (2017). TwentyFirst-Century Skills of Alternative Learning System Learners. SAGE Open, 7(3), 1-8. https://doi.org/10.1177/ 2158244017726116

Trilling, B., \& Fadel, C. (2009). 21st century skills; learning for life in our times. San Francisco: John Wiley \& Sons.

Voogt, J., \& Roblin, N. (2012). A comparative analysis of international frameworks for 21st century competences: Implications for national curriculum policies. Journal of Curriculum Studies, 44(3), 299-321. https://doi.org/10.1080 /00220272.2012.668938

Windschitl, M. (2009). Cultivating 21st century skills in science learners: How systems of teacher preparation and professional development will have to evolve. Presentation given at the National Academies of Science Workshop on 21st Century Skills, Washington, DC. Retrieved from https://sites.nationalacademies.org/cs/groups/dbassesite/ documents/webpage/dbasse_072614.pdf

Zidan, A., \& Odeh, F. (2007). The Degree of Using Creative Thinking Style by the Lower Basic Teachers of Science in the District of Hebron. IUG Journal of Humanities Research, 16(2), 667-691. Retrieved from http://www.iugaza.edu.ps/ ara/research/ 